\title{
Using Artificial Neural Networks to Determine the Extent to Which the Private Sector in the KSA Benefit from Quantitative Methods in Decision-Making
}

\author{
FUAD A. A. Awwad \\ Quantitative Analysis Department, College of Business Administration, \\ King Saud University, Riyadh, Saudi Arabia, \\ Email: fawwad@ksu.edu.sa
}

\section{Abstract:}

The goal of this research was to investigate the actuality of employing quantitative tools in decision making. The most major issues that impede the adoption of quantitative approaches in the private sector in Saudi Arabia are the key sources of managers' knowledge, decision-making styles, identifying decision-making methodologies, and sectors of applications. Data were acquired by a questionnaire survey of 594 managers, and data were analyzed descriptively and inferentially. According to the findings, 80.1 percent of respondents use quantitative techniques in decision-making; the primary sources of quantitative method expertise were university study (34\%), followed by applied practice $(26 \%)$. Furthermore, 42 percent of participants used experience as a decision-making tool. Statistical analysis was utilized as a quantitative method, accounting for $17 \%$ of the total. 
The most common fields of use for quantitative approaches were profitability analysis (12\%) and inventory control (11\%). With $30 \%$, the most common reason preventing the use of quantitative approaches was a lack of professionals. The most common benefit of applying quantitative methods mentioned by participants was an increase in profitability (28\%). In this study, we used two techniques: neural network and logistic regression. We concluded that the most important variables that have an impact on making the right decision in the private sector are academic qualification (46.6 percent), knowledge of quantitative methods (20 percent), the extent of application of quantitative methods (17.8 percent), and finally age (15.6 percent).

Keywords: Neural Network; Logistic Regression; Quantitative Methods; Information Technology; Decisions Support System.

\section{Introduction}

Managers devote significant time and effort to making sound decisions. Many scientists and practitioners regard decisionmaking as the most important and fundamental administrative activity. The vast majority of profitable business decisions rely on a reliable data source and data validation via the use of tools and models. The relevance of employing quantitative methods as a useful instrument for making choices and addressing administrative difficulties emerged in the modern period. 
The right decisions made by decision makers are also influenced by operations research. The qualitative models and techniques used in the private sector, such as the creation of goods and services, manufacturing firms that determine the lowest-cost combination of inputs required for actual production, and how best to create, in the proper number and quality for customer satisfaction. Various companies employed qualitative approaches in some aspects of decision making, such as North American academic research libraries, which used statistical methods in budgeting, collection usage, and enhancing the efficiency of specialized processes, particularly processing. Rarely have data been linked to larger institutional performance or service quality indicators. The use of quantitative tools in decision making has been a huge success.

As the world becomes more data-driven, the complexity of decision-making in the private sector, such as manufacturing, business, and medical applications, is fast expanding. Managers face a plethora of decisions every day as a result of the rapidly changing corporate environment. They must make decisions, even if they do not want to.

\section{Problem statement:}

The main issue addressed in this paper is to investigate the extent to which quantitative methods are used in decision-making in the 
private sector in Saudi Arabia, as well as to identify the constraints that limit the use of these methods and provide recommendations to address these constraints in order to substantiate the use of quantitative methods in the private sector.

\section{The study's significance:}

1. Academic level: researchers aspire to contribute to the advancement of scientific knowledge by employing quantitative decision-making methods.

2. Applied Level: This study is meant to attract decisionmakers' attention to the need of using quantitative methods in decision-making.

\section{The following are the research objectives:}

1. Recognize the reality of employing quantitative approaches in the commercial sector, as well as the key sources of managers' knowledge and decision-making styles.

2. Identify decision-making methods and application fields.

3. Identifying the most significant barriers to the application of quantitative methods.

4. Emphasizing the benefits that quantitative methodologies provide to enterprises.

5. Measuring the impact of specific variables on decision accuracy in the private sector. 


\section{Background:}

BABU (2012) conducted a study to investigate the relationship between various micro and macroeconomic aspects and to develop strategies based on data analytics. The elements influencing policymaking were technology with human-driven analytics has made the process of retrieving information easier than in the past, perfect uses of data mining and statistics necessitate the employment of computer science and client-domain knowledge. Successful knowledge discovery is dependent on coordination between the disciplines statistics-data mining, computer science, and domain expertise; if this coordination is realized, we will undoubtedly see broader applications of data mining in practically all areas of research institutes.

Hiller (2003) examined the use of quantitative approaches in decision-making and discovered that there is a considerable interest in using quantitative and qualitative data in library management and decision-making among North American academic research libraries. The study also identified a number of barriers to adopting statistical models in decision-making, such as the amount of data supplied and the length of the consultation process. Furthermore, there were few university research libraries, and information moved quickly. Above important, they lacked statistical data training and experience. 
Prior to making forecasts, Kusiak (2002) examined the accuracy connected with the decision signatures. Some decisions may demand extreme precision, while others may necessitate a degree of uncertainty. The capacity to analyse the accuracy of a decision a priori makes the presented ideas appealing to technology, business, and medical applications. The evaluation was carried out in accordance with the human factors community's group assessment and decision-making processes. The study's findings improved the quality of decision-making by utilising an algorithm. In which the decision signatures were ranked and the utility index was updated using a group decision-making method. ANENE (2014) investigated the factors that influence the use of Quantitative Techniques (QTs) in production planning in a variety of Nigerian manufacturing industries. Data were acquired via a questionnaire provided to 160 employees of 20 companies chosen at random from each of the eight purposefully selected Nigerian Small-Scale Industries. The control chart, dispersion measures (range, variance, and standard deviation), forecasting techniques (regression and time series analyses), graphical and charting techniques, inventory model, capacity utilization model, and acceptance sampling were discovered to be the QTs used by the various companies in the selected industries. Control charts, which were discovered to be the most often used strategies, account for $35 \%$ of the total. This is consistent with the findings of (Grigg and Walls 2004). In terms of frequency of application, 
dispersion measures (Range, Variance, and Standard Deviation) came in second (30 percent). Forecasting approaches (regression and time series analysis - the two traditional forecasting methods) (15\%), graphical and charting techniques (12\%), inventory model, capacity utilization, and acceptability sampling (1\%) were the least often used techniques.

Kessy (2006) provided an assessment of how widely operations research methods are used in various firms. This data was gathered from 9 examples (Tanzanian organizations) by MBA students from the University of Dar es Salaam who followed an uniform methodology devised by the researcher in order to better understand the hurdles for an application. The study discovered a low level of application of operational research (OR) techniques in the businesses studied, as well as the difficulties for model underutilization. Despite managers' awareness of the benefits of employing OR models, the models were poorly conceptualized, constructed, and used in decision-making. The presence of underqualified or well-trained employees in the OR field within organizations, a lack of experts in the OR field in the labor market, and resistance to change, which is primarily caused by conservative managers, i.e., they do not see the point in using "needless quantitative methods" were the challenges impeding the application and utilizations of operation research. Other problems included a lack of infrastructure, insufficient financial resources, a lack of management support, and opposition to 
change. The dynamic environment is the major obstacle that operation managers cannot control.

According to Fuller (2003), 13 quantitative models were used for decision making in analysis models, linear programming models, game theory models, simulation models, network optimization models, project management models, inventory models, queuing models, dynamic programming, integer programming, nonlinear programming models, forecasting models, and Markov decision models.

Valero (1997) conducted a study to investigate the status and extent to which administrators of colleges and universities in the state of Virginia. Use qualitative and quantitative management techniques in planning and controlling activities, as well as determining the sorts of managerial techniques employed, the degree of expertise with these techniques, the frequency with which they are employed, the managerial benefits and constraints, and the person and organizational aspects involved in employing such techniques The examination proceeded directly to the highest and most operational organizational levels in two categories of administrators (nonacademic and academic). According to the findings of this study, administrators had a moderate understanding of the procedures and a limited application of them. Furthermore, no statistically significant variations in the degree of familiarity and amount of use with various management strategies (qualitative and quantitative) were 
discovered, regardless of administrator assignment category (nonacademic or academic) or administrator level or type (executive or operative). Brainstorming was the most commonly mentioned strategy in terms of familiarity and breadth of use. Benchmarking checklists and cost-benefit analysis. Respondents use qualitative strategies for decision-making more positively and assess their value more favorably than quantitative ones. Itanyi (2012) sought to determine the extent to which managers use quantitative and qualitative methodologies in organizational decision-making. Investment appraisal, break-even analysis, market research, sales forecasting, critical path analysis, decision trees, chi square, correlation analysis, regression analysis, simulation, transportation analysis, and t-test are some examples of quantitative decision-making criteria that were used. The researcher discovered that the use of both qualitative and quantitative methods was critical in managerial decision-making for the efficient and effective use of available resources for the organization's growth and development. If the managers in any business are inexperienced with the various methodologies, it may have a negative impact on the organization's decisionmaking process and, as a result, its competitiveness. As a result, it is important for managers to improve their decision-making skills through the accumulation of experience and scientific knowledge. This will ensure that the organization's decision- 
making process is correct, that its communication mechanisms are effective, and that its resources are used efficiently.

A study (Turpin, 2004) attempted to reconcile a variety of theoretical decision-making theories with how senior managers actually make decisions. Six influential decision-makers were interviewed about their decision-making habits and use of decision-support technology. The study's findings revealed a large diversity in personal decision-making styles. However, several key themes emerged, such as the significance of being sensitive to the decision-making situation, paying attention to information presentation, and using intuition. In terms of decision support technology use, self-help options such as office software were clearly preferred. One of the study's surprises was that, despite having formal training in advanced decision support methods and technology, a lot of the decision-makers found little use for it in their working environment. The recognition-primed decision (RPD) model, which describes naturalistic decisionmaking, was one of the decision-making models that gained relatively significant support in concept.

\section{Methodology}

All private-sector personnel participating in decisionmaking were included in the study population. This study employs a stratified random sample method in which a corporation is chosen at random and then participants are chosen using a simple random sample. The questionnaire was issued to 
700 different businesses, and the return was (594) questionnaires with an 84.9 percent response rate.

\section{The research instrument:}

Data was obtained using a questionnaire prepared by the researcher after examining the literature on the issue and making use of it. The study was divided into two sections. The first section was a personal variable for employees (participants), such as length of service, experience and credentials, specialization, and all of these questions were near. The second section addresses a variety of significant features of quantitative approaches, such as the level of knowledge, the sources of knowledge, and the level of interest in learning them. Their application in the workplace, the sorts of procedures used, and the methods used in decision making. The reasons for not employing quantitative methods, as well as how frequently they made the correct conclusions. Following the development of the questionnaire statements, they were reviewed by a committee of specialized academics from King Saud University's departments of public administration and quantitative methods to ensure the clarity of words, language accuracy, and sincerity of the content. The approval of the resolution phrases was considered, and 
after making the necessary revisions based on the professors' suggestions regarding the tool's content.

We used the following statistical tools to fulfil the goals of this study:
(A) Frequency and percentage tables.
(B) A neural network is a type of computer network.
(C) Logistic Regression is a type of regression analysis.

\section{The Outcomes Achieved}

This section is divided into two sections. The first part offers some sample characteristics in terms of three variables: sector, size, and business ownership. Then, describe some of the individuals' socio-demographic information, such as age, occupation, and qualification. The second section provides answers to all research questions, with a focus on the most noteworthy findings.

\section{The sample's characteristics}

According to Table (1), the majority of survey participants (53.7\%) work in the industry (27.3\%) and services (24.2\%) sectors, followed by the trade sector $(24.2 \%)$ and banking and finance (8.2\%). 
Using Artificial Neural Networks to Determine the Extent to Which the Private ...

Dr/ FUAD A. A. Awwad

Table (1): Characteristics of firms where the participants work

\begin{tabular}{|l|c|c|}
\hline \multicolumn{1}{|c|}{ Business Activity } & Frequency & $\%$ \\
\hline Industry & 162 & $27.3 \%$ \\
\hline Trade & 144 & $24.2 \%$ \\
\hline Banking and Finance & 49 & $8.2 \%$ \\
\hline Services & 157 & $26.4 \%$ \\
\hline Warehousing and Distribution & 2 & $.3 \%$ \\
\hline Agribusiness (agricultures) & 30 & $5.1 \%$ \\
\hline Other Total & 50 & $8.4 \%$ \\
\hline \multicolumn{1}{|c|}{ Firm's size (number of employees) } & Frequency & $\%$ \\
\hline Less than 50 employees & 198 & $33.3 \%$ \\
\hline More than 50 employees & 396 & $66.7 \%$ \\
\hline Total & 594 & 100 \\
\hline Total & Frequency & $\%$ \\
\hline Ownership of the company & 125 & $21.0 \%$ \\
\hline Special & 469 & $79.0 \%$ \\
\hline Oneral & 594 & 100 \\
\hline
\end{tabular}

In contrast, only 0.3 percent work in warehousing and distribution, and 5.1 percent work in agriculture. The second section of the table likewise shows that the majority of survey participants (66.7 percent) work in large-sized organizations with 
more than 50 workers, while 33.3 percent work in small-sized companies with fewer than 50 employees. While the last section of the table shows that the bulk of research participants work for privately held businesses.

Table (2) depicts some of the characteristics of the participants, for example, young people account for 77.4 percent of the study sample individuals aged 40 or less, followed by 17.7 percent of respondents aged 41 to 50 years, and those aged more than 50 years account for no more than 4.9 percent of the participants. The second part of the table shows the distribution of the sample based on job position, and it is clear that those who occupy the functional head of department (30.1 percent) have the highest percentage, followed by functions other than those represented in the question (21.5 percent), and then assistant director and director of administration (27.3 percent). General managers and their assistants make up $21 \%$ of the sample. In summary, the majority of respondents work in managerial roles where they are obliged to make choices, with 78.5 percent holding at least the position of head of department. Part 3 of the table shows the sample distribution by educational qualification, with 55.7 percent having a college degree, 36.9 percent having a diploma certificate to high school, 5.1 percent having an advanced degree, and 2.4 percent having less than a high school qualification. 
Using Artificial Neural Networks to Determine the Extent to Which the Private ...

Dr/ FUAD A. A. Awwad

Table (2): Participants' socio-demographic information

\begin{tabular}{|c|c|c|}
\hline$\overline{\text { Age }}$ & Frequencies & $\%$ \\
\hline $20-30$ & 214 & $36.0 \%$ \\
\hline $31-40$ & 246 & $41.4 \%$ \\
\hline $41-50$ & 105 & $17.7 \%$ \\
\hline More than 50 & 29 & $4.9 \%$ \\
\hline Total & 594 & 100 \\
\hline Occupation & Frequencies & $\%$ \\
\hline General manager & 70 & $11.8 \%$ \\
\hline Assistant general manager & 55 & $9.3 \%$ \\
\hline Director of the administration & 86 & $14.5 \%$ \\
\hline Assistant Director of the administration & 76 & $12.8 \%$ \\
\hline Head of Department & 179 & $30.1 \%$ \\
\hline Other & 128 & $21.5 \%$ \\
\hline Total & $\overline{594}$ & 100 \\
\hline Qualification & Frequencies & $\%$ \\
\hline Less than High School & 14 & $2.4 \%$ \\
\hline High School & 95 & $16.0 \%$ \\
\hline Diploma (two or three years) & 124 & $20.9 \%$ \\
\hline Parchment(college degree) & 331 & $55.7 \%$ \\
\hline postgraduate degree (Master and over) & 30 & $5.1 \%$ \\
\hline Total & 594 & 100 \\
\hline
\end{tabular}

\section{Answering the research questions}

Q1: Where do you get your information about quantitative methods?

According to table (3), university study is considered to be the largest source of knowledge of quantitative methods, accounting for $34 \%$, followed by applied practise (26\%), training courses $(24 \%)$, and books and references (8\%). It should be noted that the total 
Using Artificial Neural Networks to Determine the Extent to Which the Private ...

Dr/ FUAD A. A. Awwad

number of replies is greater than the number of sample participants since it allows participants to select more than one option.

Table (3): Knowledge sources for quantitative approaches

\begin{tabular}{|l|l|c|c|c|}
\hline \multirow{2}{*}{ The question and levels of answer } & \multicolumn{3}{c|}{ Responses } \\
\cline { 3 - 5 } & $\mathrm{N}$ & $\%$ & Rank \\
\hline \multirow{3}{*}{$\begin{array}{l}\text { Knowledge } \\
\text { sources for } \\
\text { quantitative } \\
\text { approaches }\end{array}$} & University study & 220 & 34 & 1 \\
\cline { 2 - 5 } & Applied Practice & 170 & 26 & 2 \\
\cline { 2 - 5 } & Other & 155 & 24 & 3 \\
\cline { 2 - 5 } & Books and references & 50 & 8 & 5 \\
\hline & Total & 649 & & 100 \\
\hline
\end{tabular}

\section{Q2: What decision-making style do you use?}

Table (4) depicts the decision-making techniques, with 42.2 percent of participants utilizing prior experience as the decision-making method, followed by 28 percent consulting, 11.3 percent personal judgement, and 18.5 percent alternative methods, trial and error, and feeling and guess work. It should be noted that the total number of answers is greater than the number of sample participants because the participants might select more than one option. 
Using Artificial Neural Networks to Determine the Extent to Which the Private ...

Dr/ FUAD A. A. Awwad

Table( 4): Decision-making's styles do you use?

\begin{tabular}{|l|l|c|c|c|}
\hline \multicolumn{2}{|c|}{ Question and levels of answer } & \multicolumn{3}{|c|}{ Responses } \\
\cline { 3 - 5 } & Previous Experience & 299 & 42.2 & 1 \\
\hline \multirow{4}{*}{$\begin{array}{l}\text { Decision-making's } \\
\text { styles used }\end{array}$} & Consulting & 198 & 28.0 & 2 \\
\cline { 2 - 5 } & Personal judgment & 80 & 11.3 & 3 \\
\cline { 2 - 5 } & Other & 48 & 6.8 & 4 \\
\cline { 2 - 5 } & Trial and error & 45 & 6.4 & 5 \\
\cline { 2 - 5 } & Feeling and guessing & 38 & 5.3 & 6 \\
\hline \multicolumn{2}{|c|}{ Total } & 708 & \multicolumn{2}{|c}{100.0} \\
\hline
\end{tabular}

\section{Q3: What quantitative methodologies are employed?}

Table (5) demonstrates that statistical analysis is the most commonly utilized quantitative method (17\%), followed by 
Using Artificial Neural Networks to Determine the Extent to Which the Private ...

Dr/ FUAD A. A. Awwad

Table (5): Quantitative methods used

\begin{tabular}{|l|l|c|c|c|}
\hline \multicolumn{2}{|c|}{ Question and levels of answer } & \multicolumn{3}{|c|}{ Responses } \\
\cline { 2 - 5 } & Statistical Analysis & N & $\%$ & Rank \\
\cline { 2 - 5 } & Prediction models & 136 & 17 & 1 \\
\cline { 2 - 5 } & Linear Programming & 107 & 13 & 2 \\
\cline { 2 - 5 } $\begin{array}{l}\text { Quantitative } \\
\text { methods }\end{array}$ & Inventory models & 91 & 11 & 3 \\
\cline { 2 - 5 } & Financial models & 85 & 10 & 4 \\
\cline { 2 - 5 } & Computer simulation & 81 & 10 & 5 \\
\cline { 2 - 5 } & Cost-benefit analysis & 79 & 10 & 6 \\
\cline { 2 - 5 } & Other & 60 & 7 & 8 \\
\cline { 2 - 5 } & Decision Tree & 50 & 6 & 9 \\
\cline { 2 - 5 } & Queuing Theory & 39 & 5 & 10 \\
\cline { 2 - 5 } & Bert model & 7 & 1 & 11 \\
\hline
\end{tabular}

prediction models (13\%), and linear programming (11\%). Whereas ten percent of participants use each of four methodologies, namely inventory models, financial models, computer simulation, and cost-benefit analysis. Finally, decision trees, queuing theory, and the Bert model are the less 
quantitative methods that are often used, accounting for $7 \%$, $6 \%, 5 \%$, and $1 \%$, respectively.

\section{Q4: In what domains do you use quantitative methods?}

According to Table (6), the most common fields of use for quantitative approaches are profitability analysis (12\%), inventory control (11\%), and sales analysis ( $10 \%)$. Production scheduling and quality control both draw a comparable percentage of participants (9\%). Another three fields, accounting procedures, project scheduling, and others, have used quantitative methods at a comparable rate of $9 \%$. Pricing is the field that uses quantitative methods the least, accounting for $3 \%$ of all fields.

\section{Q5: What are the causes for the lack of use of quantitative methods?}

The most common reason for not employing quantitative approaches is a lack of professionals (30\%). A quarter or less of the participants cite three reasons for not using quantitative approaches: 14 percent cite a lack of expertise of these methods, 11 percent cite a lack of management attention, and 10 percent cite a lack of reliable data availability. The least prevalent explanations, which account for 3\% of all cases, are a lack of computer access and "used but did not succeed," as indicated in Table (7). 
Using Artificial Neural Networks to Determine the Extent to Which the Private ...

Dr/ FUAD A. A. Awwad

Table (6): Fields of applying quantitative methods

\begin{tabular}{|c|c|c|c|c|}
\hline \multirow{2}{*}{\multicolumn{2}{|c|}{ Question and the levels of answer }} & \multicolumn{3}{|c|}{ Responses } \\
\hline & & $\mathrm{N}$ & $\%$ & Rank \\
\hline \multirow{13}{*}{ Fields } & Profitability analysis & 116 & 12 & 1 \\
\hline & Inventory control & 103 & 11 & 2 \\
\hline & Sales Analysis & 97 & 10 & 3 \\
\hline & Production schedule & 85 & 9 & 4 \\
\hline & Quality Control & 81 & 9 & 5 \\
\hline & Accounting procedures & 76 & 8 & 6 \\
\hline & The project schedule & 75 & 8 & 7 \\
\hline & Other & 73 & 8 & 8 \\
\hline & Manpower Planning & 66 & 7 & 9 \\
\hline & Allocation of resources & 56 & 6 & 10 \\
\hline & Capacity planning & 45 & 5 & 11 \\
\hline & Maintenance and repair & 33 & 4 & 12 \\
\hline & Pricing & 31 & 3 & 13 \\
\hline & Total & 937 & & \\
\hline
\end{tabular}


Using Artificial Neural Networks to Determine the Extent to Which the Private ...

Dr/ FUAD A. A. Awwad

Table(7): The reasons for not using quantitative methods

\begin{tabular}{|c|c|c|c|c|}
\hline \multirow{2}{*}{\multicolumn{2}{|c|}{ The question and levels of answer }} & \multicolumn{3}{|c|}{ Responses } \\
\hline & & \multirow{2}{*}{$\frac{\mathrm{N}}{169}$} & \multirow{2}{*}{$\frac{\%}{30}$} & \multirow{2}{*}{$\frac{\text { Rank }}{1}$} \\
\hline \multirow{12}{*}{ Reasons } & Unavailability of specialists & & & \\
\hline & Lack of knowledge of these methods & 81 & 14 & 2 \\
\hline & Lack of management attention & 64 & 11 & 3 \\
\hline & Lack of accurate data availability & 59 & 10 & 4 \\
\hline & $\begin{array}{l}\text { The firm is successful without using } \\
\text { these methods }\end{array}$ & 31 & 6 & 5 \\
\hline & Lack of necessary funds & 30 & 5 & 6 \\
\hline & $\begin{array}{l}\text { Lack of encouragement from } \\
\text { chairpersons }\end{array}$ & 29 & 5 & 7 \\
\hline & High cost & 28 & 5 & 8 \\
\hline & The firm is a small size & 25 & 4 & 9 \\
\hline & Other reasons & 23 & 4 & 10 \\
\hline & Lack of availability of computer & 14 & 3 & 11 \\
\hline & Used but did not success & 14 & 3 & 12 \\
\hline & Total & 567 & & \\
\hline
\end{tabular}

Q6: What are the advantages of employing quantitative methods?

According to table (8), the most common benefits of employing quantitative methods mentioned by survey participants are improved profitability $(28 \%)$, cost reduction (19\%), and time savings (19\%). "Other benefits" account for $1 \%$ of the benefits reported by participants. 
Using Artificial Neural Networks to Determine the Extent to Which the Private ...

Dr/ FUAD A. A. Awwad

Table (8): The benefits of using quantitative methods

\begin{tabular}{|c|l|c|c|c|}
\hline \multicolumn{2}{|c|}{ Question and levels of answer } & \multicolumn{3}{|c|}{ Responses } \\
\cline { 2 - 5 } & Improve profitability & N & $\%$ & Rank \\
\cline { 2 - 5 } & Reduce costs & 156 & 19 & 2 \\
\cline { 2 - 5 } & Save time & 154 & 19 & 3 \\
\cline { 2 - 5 } $\begin{array}{c}\text { Benefits of using } \\
\text { Quantitative } \\
\text { methods }\end{array}$ & Improve productivity & 141 & 18 & 4 \\
\cline { 2 - 5 } & $\begin{array}{l}\text { Improve the decision-making } \\
\text { process }\end{array}$ & 117 & 15 & 5 \\
\cline { 2 - 5 } & Other & 10 & 1 & 6 \\
\hline \multicolumn{2}{|c|}{807} & \multicolumn{2}{|c|}{100} \\
\hline
\end{tabular}

\section{Q7: Do you use quantitative methods to make decisions?}

When asked if they use quantitative methods or not, it was discovered that 80.1 percent of respondents use quantitative approaches in decision-making, whereas 19.9 percent do not (see table (9)).

Table (9): Extent of applying quantitative methods in decision-making

\begin{tabular}{|c|c|c|}
\hline \multicolumn{1}{|c|}{ Answers } & Frequencies & \% \\
\hline Applied & 476 & 80.1 \\
\hline Non applied & 118 & 19.9 \\
\hline Total & 594 & 100 \\
\hline
\end{tabular}

Q8: How frequently do you make good decisions?

How often do the participants make the correct decision? This is demonstrated in table 10, where the majority of 49.3 percent say that their decisions are frequently correct (correct) and 13.8 percent 
Using Artificial Neural Networks to Determine the Extent to Which the Private ...

Dr/ FUAD A. A. Awwad

indicate that their decisions are always correct, for a total of 63.1 percent, which is by no means low. While only 4.1 percent of participants make proper selections on a regular or seldom basis. Those in the middle account for 32.8 percent of all participants.

Table (10): The frequency of making the right decisions

\begin{tabular}{|l|c|c|}
\hline \multicolumn{1}{|c|}{ Answers } & frequencies & \% \\
\hline Never & 7 & 1.2 \\
\hline Rarely & 17 & 2.9 \\
\hline Sometimes & 195 & 32.8 \\
\hline Often & 293 & 49.3 \\
\hline Always TOTAL & 82 & 13.8 \\
\hline & 594 & 100.0 \\
\hline
\end{tabular}

Those in the middle account for 32.8 percent of all participants. There have been Merged answers are combined (always, frequently) to indicate correct decisions and (never, rarely, occasionally) to symbolize incorrect decisions, with table (11) displaying the majority. 63.1 percent made accurate decisions, whereas 36.9 percent made incorrect decisions. 
Using Artificial Neural Networks to Determine the Extent to Which the Private ...

Dr/ FUAD A. A. Awwad

Table (11): the accuracy of the decision-making

\begin{tabular}{|c|c|c|}
\hline Answers & frequencies & $\%$ \\
\hline non correct & 219 & 36.9 \\
\hline Correct & 375 & 63.1 \\
\hline Total & 594 & 100.0 \\
\hline
\end{tabular}

We have two components covered under two axes: the first is the extent of quantitative techniques use, and the second is quantitative methods. Whereas the first axis includes the application of quantitative methods to questions $(14,16,9,8,15)$, and the second axis includes special knowledge regarding Quantitative Methods questions $(10,13,12)$, the two axes represent the independent variables influencing decision-making accuracy (the dependent variable). The quartiles approach was used to divide the categories and merge them using the sum of the scores.

Table (12) illustrates the extent of the application of quantitative methods

\begin{tabular}{|c|c|c|}
\hline & Frequency & Percent \\
\hline Low & 195 & 32.8 \\
\hline Medium & 277 & 46.6 \\
\hline High & 122 & 20.5 \\
\hline Total & 594 & 100.0 \\
\hline
\end{tabular}


Illustrates table (12) applied the quantitative methods $46.6 \%$ with a Medium degree while $32.8 \%$ applied the quantitative methods with a low degree

Table (13) knowledge regarding Quantitative Methods

\begin{tabular}{|c|c|c|}
\hline & Frequency & Percent \\
\hline low & 238 & 40.1 \\
\hline Medium & 212 & 35.7 \\
\hline High & 144 & 24.2 \\
\hline Total & 594 & 100.0 \\
\hline
\end{tabular}

Table (13) depicts the knowledge with Quantitative Methods with a high degree of roughly a quarter 24.2 percent vs 40.1 percent knowledge with Quantitative Methods.

\section{Models And Analytical Hypotheses}

We used a Neural network and Logistic regression to determine the important aspects that influence decision-making. The term "Neural Network" refers to the nervous system as an adjective. Neural networks, also known as Artificial Neural Networks, function similarly to neurons in the human brain. It acquires knowledge through the learning process, much as the human mind does from past experiences. Different from traditional methods, neural networks provide an appropriate way to represent relationships between variables. Neural networks are known as artificially intelligent neural network models, which do not require the availability of restricted assumptions about the 
relationship between dependent variables and independent variables; neural networks treat non-parametric data with a high degree of accuracy. Logistic regression analysis investigates the relationship between a categorical dependent variable and a set of independent (explanatory) variables. Linear logistic regression models are one of the most prominent models used to create the discriminant function (no\& Yes)

We have two components covered: the first is the extent of quantitative techniques use, and the second is quantitative methods. Whereas the first axis includes the application of quantitative techniques to questions $(14,16,9,8,15)$, and the second axis includes particular knowledge regarding quantitative methods questions $(10,13,12)$, the two axes indicate the independent variables influencing the decision-making accuracy (the dependent variable).

The data was processed by integrating the variables that represent the independent variables, and categories were divided using quartiles, in order to build models capable of predicting decisionmaking accuracy, the extent of the use of quantitative methods in decision-making in the Saudi private sector, and the relative importance of the determinants influencing decision-making accuracy. We employed Neural networks are one of the ways of artificial intelligence in general, and one of the methods of machine learning in particular, because they provide a novel 
Using Artificial Neural Networks to Determine the Extent to Which the Private ...

Dr/ FUAD A. A. Awwad

approach to describe the correlations between variables than traditional methods.

\section{Figure (1) Multilayer Perceptron - Architecture of Neural Network}

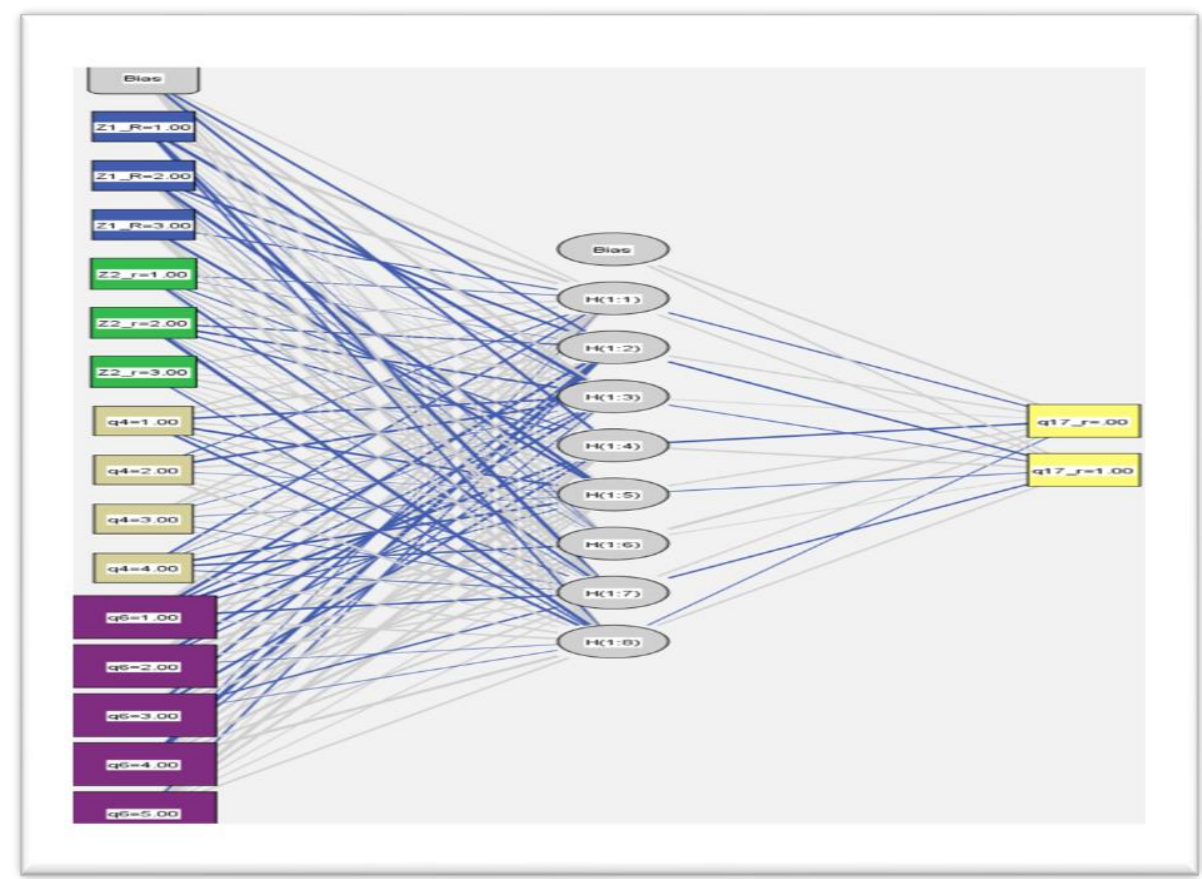

The data was processed, and the networks were trained on it, which means the network learned and recognized all information as well as the link between the various variables. The network inputs were represented by four independent determinants, with the following results 
Using Artificial Neural Networks to Determine the Extent to Which the Private ...

Dr/ FUAD A. A. Awwad

Table (14) Classification model

\begin{tabular}{|c|c|c|c|c|}
\hline \multicolumn{2}{|c|}{ Sample } & \multicolumn{3}{c|}{ Predicted } \\
\cline { 3 - 5 } & No & yes & Percent Correct \\
\hline \multirow{3}{*}{ Training } & false & 79 & 79 & $50.0 \%$ \\
\cline { 2 - 5 } & true & 51 & 227 & $81.7 \%$ \\
\cline { 2 - 5 } & Overall Percent & $29.8 \%$ & $70.2 \%$ & $70.2 \%$ \\
\hline \multirow{3}{*}{ Testing } & false & 32 & 29 & $52.5 \%$ \\
\cline { 2 - 5 } & true & 16 & 81 & $83.5 \%$ \\
\cline { 2 - 5 } & Overall Percent & $30.4 \%$ & $69.6 \%$ & $71.5 \%$ \\
\hline & Dependent Variable: the accuracy of the decision-making \\
\hline
\end{tabular}

According to the previous table, the overall percentage of correct prediction is 70.2 percent, while the percentage of incorrect forecast is 29.8 percent. This signifies that the sum of correct predictions and incorrect predictions equals 100 percent.

Table (15) Importance of Independent Variables

\begin{tabular}{|l|c|c|}
\hline & Importance & $\begin{array}{c}\text { Normalized } \\
\text { Importance }\end{array}$ \\
\hline $\begin{array}{l}\text { the extent of the application of quantitative } \\
\text { methods }\end{array}$ & 0.178 & $38.2 \%$ \\
\hline knowledge regarding Quantitative Methods & 0.200 & $42.9 \%$ \\
\hline Age & 0.156 & $33.5 \%$ \\
\hline Qualification & 0.466 & $100.0 \%$ \\
\hline
\end{tabular}

The relative importance of the variables in the previous table that the academic qualification came in first place, followed 
by the educational qualification 46.6 percent, knowledge regarding quantitative methods 20 percent, the extent of the application of quantitative methods 17.8 percent, and finally age 15.6 percent, figure shows

Figure (2) Indicators of Importance

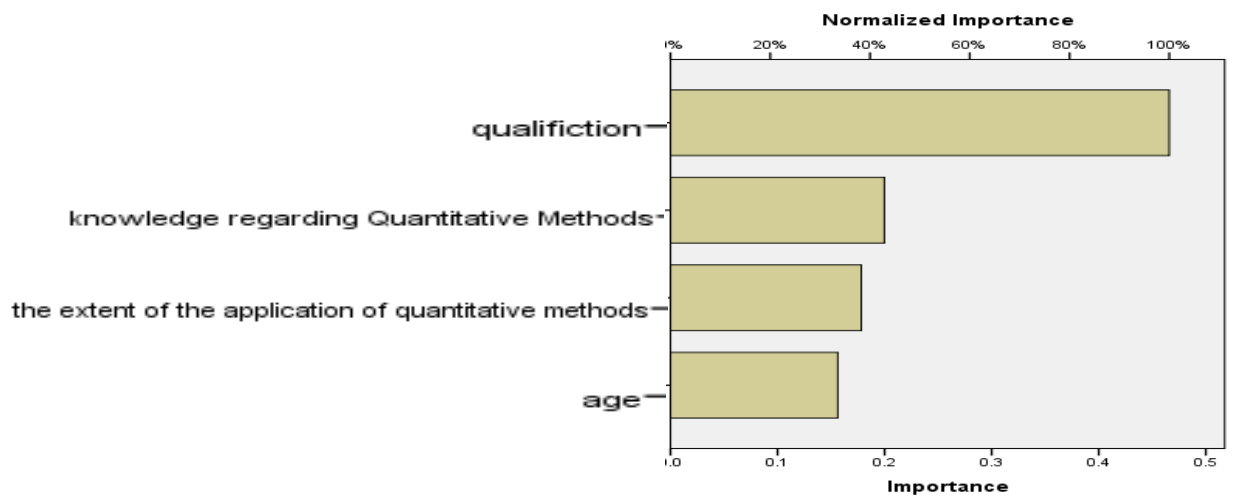

The previous Figure depicts the normalized relevance of each predictive variable. This is basically a bar chart with importance values sorted in descending order. Normalized importance is a measure of how much the predicted value of the dependent variable would be affected by the exclusion of a specific predictive indicator. The educational qualification was ranked first in terms of importance, followed by knowledge of Quantitative Methods in second place, and then the extent of quantitative method application in third place and finally the age. 
The logistic linear regression model is one of the most important models used to formulate the discrimination function, and this model is characterized by its suitability for many uses, and logistic regression is used in general to analyze the relationship between the use of quantitative methods to support and decision-making or not.

Logistic regression arises from using the previous logit transformation when the dependent variable $(\mathrm{Y})$ expresses the probability of a certain event $(\theta)$, and there is a set of explanatory variables $X=\left\{X_{1}, X_{2}, \ldots, X_{p}\right\}$ whose number is $P$ variable, and there is a relationship between Probability $(\theta)$ and explanatory variables on the following linear form:

$$
\theta_{k}=\beta_{0}+\beta_{1} x_{1 k}+\beta_{2} x_{2 k}+\ldots+\beta_{p} x_{p k}
$$

Since the left side is finite $(0<\theta<1)$ while the right side of the equation is infinite, and using the logit transformation we get that:

$$
\mathrm{P}_{r}\left(\mathrm{Y}_{k}=1 / X\right)=\frac{\exp \left(\beta^{`} \mathrm{X}\right)}{1+\exp \left(\beta^{\prime} \mathrm{X}\right)}=\mathrm{P}_{r}(\mathrm{X})
$$

The logit transformation, which is the basis for this model, is known as:

$$
g(X)=\operatorname{Ln}\left(\frac{\mathrm{P}_{r}(\mathrm{X})}{1-\mathrm{P}_{r}(\mathrm{X})}\right)=\beta^{\prime} \mathrm{X}
$$


Assumptions of the logistic linear regression model are

1. The dependent variable is a binary or multiple nominal variable. The conditional expectation for this variable $\mathrm{E}(\mathrm{y} \mid \mathrm{x})$ is a variable limited to the period $(0,1)$. As for the explanatory variables, they can be continuous or discontinuous, nominal binary or multiple, as it is assumed that all Variables are measured without errors.

2. The dependent variable and the explanatory variables have a substantial relationship.

3. The expected value of the random error is zero, the variance of the random error is constant, and the random error $\left(\mathrm{u}_{\mathrm{k}}\right)$ follows a binomial distribution with a probability determined based on the conditional mean.

4. There is no correlation between random errors (independence errors).

5. There is no correlation between random error and explanatory variables.

6. There is no complete correlation between the explanatory variables.

\section{Data application}

The analysis included 594 questionnaires, and the following are the features of the estimated model, which included four independent variables using the logistic linear regression model at a level of significance of $5 \%$. The classification table is 
Using Artificial Neural Networks to Determine the Extent to Which the Private ...

Dr/ FUAD A. A. Awwad

another method to evaluate the predictive accuracy of the logistic regression model

Table (16) The System of Classification

\begin{tabular}{|c|c|c|c|c|}
\hline \multirow{3}{*}{\multicolumn{2}{|c|}{ Observed }} & \multicolumn{3}{|c|}{ Predicted } \\
\hline & & \multicolumn{3}{|c|}{ the accuracy of the decision-making } \\
\hline & & No & yes & Percentage Correct \\
\hline \multirow{3}{*}{$\begin{array}{l}\text { the accuracy of the } \\
\text { decision-making }\end{array}$} & No & 85 & 134 & 38.8 \\
\hline & Yes & 58 & 317 & 84.5 \\
\hline & $\begin{array}{l}\text { Overall } \\
\text { Percentage }\end{array}$ & & & 67.7 \\
\hline
\end{tabular}

According to the previous table, the total classification degree for the model has achieved 67.7 percent, with the right predicted amounting to 84.5 percent.

Table (17) The strength of the relationship between dependent and independent variables

\begin{tabular}{|l|c|c|c|c|c|c|}
\hline \multicolumn{1}{|c|}{ Independent variables } & B & S.E. & Wald & df & Sig. & Exp (B) \\
\hline $\begin{array}{l}\text { the extent of the application of } \\
\text { quantitative methods }\end{array}$ & -0.18 & 0.13 & 1.95 & 1.00 & 0.16 & 0.83 \\
\hline $\begin{array}{l}\text { knowledge regarding } \\
\text { Quantitative Methods }\end{array}$ & $\mathbf{0 . 3 6}$ & 0.12 & 8.38 & 1.00 & $\mathbf{0 . 0 0}$ & $\mathbf{1 . 4 3}$ \\
\hline age & 0.04 & 0.11 & 0.16 & 1.00 & 0.69 & 1.05 \\
\hline qualification & $\mathbf{0 . 6 4}$ & 0.11 & 36.17 & 1.00 & $\mathbf{0 . 0 0}$ & $\mathbf{1 . 8 9}$ \\
\hline Constant & -2.01 & 0.43 & 22.11 & 1.00 & 0.00 & 0.13 \\
\hline
\end{tabular}

The previous table demonstrates that education level has a positive effect on decision-making, 0.64, which is significant because the $\mathrm{P}$-value is smaller than 0.05 . The odds ratio demonstrates that as a person's education level improved, so did 
their chances of making the right selection. Furthermore, the understanding quantitative approaches have a favorable effect on the decision, 0.36, and its coefficient is significant at the level of 0.05 . When understanding of quantitative methods improved, the odds ratio climbed by 1.5 , indicating that the chance of making the correct decision increased by 1.5 . While both age and the extent to which quantitative approaches are used have a negligible impact on decision making.

Table (16) reveals that 85 items were correctly split at a rate of 38.8 percent out of 219 items that did not apply quantitative decision support systems, and 317 items were successfully divided at a rate of 84.5 percent out of 375 items that used quantitative decision support systems. It is also obvious that the number of 402 things was successfully divided, with a percentage of 67.7 percent out of the sample size of 594 items.

\section{Table (18) Dimensions of the curve}

\begin{tabular}{|c|c|c|c|c|}
\hline \multicolumn{2}{|c|}{ Area Under the Curve } \\
\hline \multirow{2}{*}{ Area } & $\begin{array}{c}\text { Std. } \\
\text { Error }\end{array}$ & Asymptotic Sig & \multicolumn{2}{|c|}{ Asymptotic 95\% Confidence Interval } \\
\cline { 3 - 5 } & & & Lower Bound & Upper Bound \\
\hline $\mathbf{0 . 7 0 2}$ & 0.022 & 0 & 0.659 & 0.745 \\
\hline
\end{tabular}


Figure (3) ROC Curve

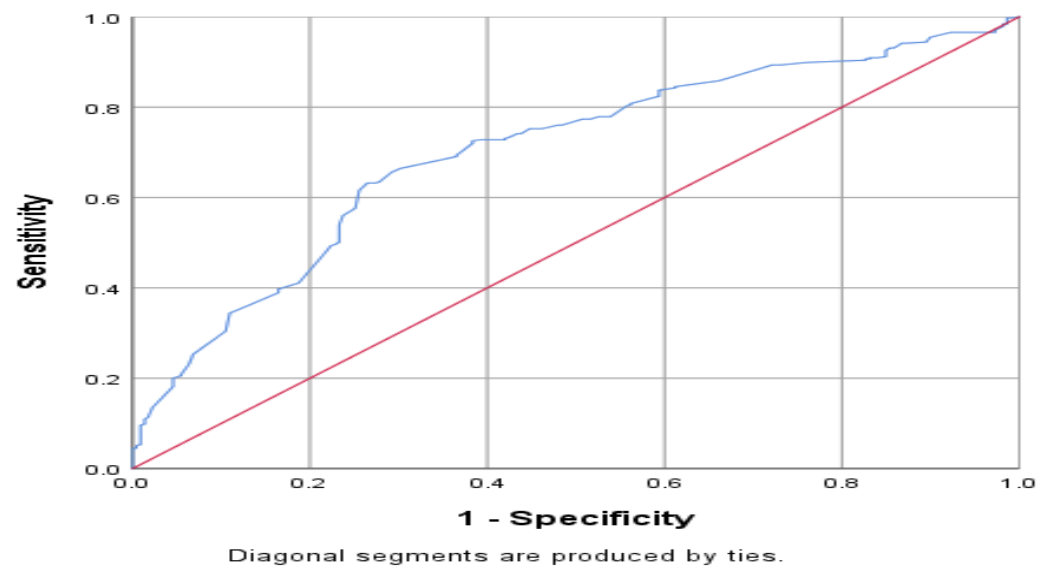

The area under the rock curve (Roc Curve) was calculated to quantify the sensitivity of the model in classification, and it reached 0.702, as in table (18), which is excellent and significant (0.000), indicating that the logistic regression is classed in a more significant and better way to predict.

\section{Conclusion and Recommendations}

According to the findings of this study, the degree of education and mastery of quantitative methods are the most essential factors in making the appropriate decision in the private sector. As well as expertise and qualifications of decision makers, the adoption of appropriate decision-making models and tools is essential to effective decision-making. Managers must improve their knowledge of models and management tools in order to reap the benefits of quantitative approaches. Quantitative analysis 
must be used by managers in every facet of their enterprises. The lack of quantitative analysis specialists was the biggest problem for the management. Managers in various organizations must have both human relations skills and technical competence to make successful and efficient decisions.

1. Behavioral approaches and quantitative techniques in businesses are closely related and should be used to solve problems because they are important productivity instruments.

2. The managers should think about the three key essential variables which are environment, technology and people, before making a decision.

3. Expansion of training for managers on the use of quantitative methods in decision-making

4. Establishing a Centre to assist managers in decision-making and in collecting the essential precise data to aid them in decision-making

5. Because of the practical and realistic attitude, quantitative methods should be included in management approaches.

6. Machines and software needed in decision-making must be provided, purchased, and upgraded.

7. The application of quantitative methods in decision making and increasing managers' understanding of decision making are among the topics that will be discussed at conferences and seminars in this area. 
8. The business sector should have access to a quantitative techniques expert who can assist managers and decision makers to better reason their actions.

\section{Acknowledgments}

The author would like to express gratitude to the Deanship of Scientific Research at King Saud University, as represented by the Research Center at CBA, for financially supporting this research.

\section{References:}

1. Al-Tarawneh, H. A. (2012). The Main Factors Beyond Decision Making. Journal Of Management Research, 4(1).

2. Andrew, K. (2002). Data Mining and Decision Making, Proceedings of SPIE - The International Society for Optical Engineering 4730:155-165.

3. Anene, E. and Oyelere, B. (2014). An Evaluation of the Applications of Quantitative Techniques to Production Planning and Control in Manufacturing Industries. European Journal of Business and Management, Vol.6, No.18.

4. Babu, Balaram (2012). Data Mining: A Source For Creative Decision Making, Asia Pacific Journal of Marketing \& Management Review. Asia Pacific Journal of Marketing \& Management Review Vol.1 No. 2.

5. Boghean, F. (2020) Integrating Risk Management into Decision Making. Conference: The 16th Economic International Conference New Challenges and Opportunities for the Economy 4.0, May 7-8th, 2020, Suceava, Romania. 
Using Artificial Neural Networks to Determine the Extent to Which the Private ...

Dr/ FUAD A. A. Awwad

6. Fuller, J. A., \& Mansour, A. H. (2003). Operations management and operations research: a historical and relational perspective. Management Decision, 41(4), 422-426.

7. Gaardboe, R. and Jonasen, T (2018) Business Intelligence Success Factors: A Literature Review. Journal of Information Technology Management. Vol. 29, No. 1, 1-15.

8. Hiller, S. (2003). "But What Does It Mean?" Using Statistical Data for Decision Making in Academic Libraries." Statistics in Practice Measuring and Managing, Proceeding of the IFLA Satellite Conference, Loughborough (England), August 2002. Library and Information Statistics Unit (LISU) Occasional Paper No. 32, 10-23.

9. Kessy, S., \& Dominic, T. (2008) Application of Operations Research Tools in Organizations: Lessons from Selected Tanzanian Firms Paper Submitted for the 4 th International Operations Research Society of East Africa (ORSEA) Conference.

10. Kumar, A. and Krishnamoorthy, B. (2020) Business Analytics Adoption in Firms: A Qualitative Study Elaborating TOE Framework in India. International Journal of Global Business and Competitiveness Vol. 15, 80-93.

11. Kusiak, A. (2002) Data Mining and Decision Making, Proceedings of SPIE - The International Society for Optical Engineering 4730:155-165.

12. Okechukwu, I., Uzoma, J., Ewurum, F. and Ukpered, W. I. (2012) Evaluation of decision-making criteria with special reference to quantitative and qualitative paradigms. African Journal of Business Management Vol.6 (44), 11110-11117. 
Using Artificial Neural Networks to Determine the Extent to Which the Private ...

Dr/ FUAD A. A. Awwad

13. Shi, Y. (2007) Today's Solution and Tomorrow's Problem: the business process outsourcing risk management puzzle, California Management Review.

14. Siddiqui, M. H., \& Tripathi, S. N. (2011). Application of Soft Operations Research for Enhancing the Servicescape as a Facilitator. Vikalpa: The Journal for Decision Makers, 36(1), 33.

15. Turpin, S. M., \& Marais, M. A. (2006). Decision-making: Theory and practice. ORiON: The Journal of ORSSA, 20(2), 143-160.

16. Valero, C. A. (1997). Applications of qualitative and quantitative techniques of management in administrative/academic Decision-making in institutions of higher education in Virginia (Doctoral dissertation, Virginia Polytechnic Institute and State University).

17. Yeh, S. and Walter, Z. (2016). Critical Success Factors for Integrated Library System Implementation in Academic Libraries: A Qualitative Study. Information Technology and Libraries. No. 9, 27-42. 